\title{
TRANSFORMACIONES RECIENTES \\ EN LA AGRICULTURA ANDALUZA
}

\author{
Josefina CRUZ VILLALON *
}

Al ser consciente de cuál es la imagen más difundida de la agricultura andaluza - pero no por ello menos correcta一, así como al valorar el carácter esencialmente divulgativo de este artículo, quisiera tomar dos ideas como punto de partida. En primer lugar, la diversidad física del espacio andaluz, que conlleva que no pueda hablarse de una agricultura andaluza, sino de múltiples y diversificadas agriculturas andaluzas (E. R. A., 1980), así como, y en consecuencia, de variados paisajes rurales. En segundo lugar quiero insistir en las profundas transformaciones que viene experimentando el agro andaluz en los últimos veinte-veinticinco años, de forma tal que la agricultura que hoy se practica difiere sustancialmente de la concepción tradicional que de la misma se tiene.

No es este el momento de realizar una exposición detallada de las condiciones del medio natural de Andalucía, pero sí de matizar la idea tópica y estereotipada de una Andalucía llana y de suelos muy fértiles; la imagen de las feroces campiñas andaluzas, que tanto han contribuido a difundir, durante los siglos pasados, los viajeros europeos por estas tierras del sur, y que hoy repiten, en términos más actualizados, quienes hablan de Andalucía como la California española, e incluso como la California europea; la Andalucía a la que, al parecer, tanto temen los agricultores de la Comunidad Europea. Ciertamente, esta Andalucía existe, pero no es, ni mucho menos, toda Andalucía.

Nuestra región, que es, con diferencia, la más extensa del territorio español $\left(87.268 \mathrm{Km}^{2}=17{ }^{\prime} 3 \%\right)$ y que duplica la superficie de algunas naciones europeas (caso de Suiza o Dinamarca), no puede, por sus mismas dimensiones, resolverse en una región de características físicas homogéneas. A grandes rasgos está formada por tres conjuntos morfoestructurales, dispuestos paralelamente en dirección NoresteSuroeste: Sierra Morena, Depresión del Guadalquivir y Cordilleras Béticas.

Sierra Morena se extiende al Norte de la región, por las provincias de Jaén, Córdoba, Sevilla y Huelva, y ocupa una superficie de $18.000 \mathrm{Km}^{2}$, aproximadamente. Constituye el reborde meridional de la Meseta, mạcizo de formación paleozoica, que se vio afectado y rejuvenecido por la orogenia alpina; en cualquier caso, no su-

* Profesora adjunta de Geografía General y de España, Universidad de Sevilla. 
pera los 1.000 metros de altitud y se caracteriza por el predominio de formas redondeadas y aplanadas por la acción erosiva de los afluentes de la margen derecha del Guadalquivir, que han provocado, a su vez, la individualización de pequeñas unidades serranas. A pesar de su escasa altitud, la pendiente y las condiciones climáticas dominantes hacen partícipe a Sierra Morena de la problemática propia de la montaña media mediterránea, en cuanto a posibilidades de aprovechamiento agropecuario, escaso desarrollo y erosionabilidad de los suelos, etc.

La Depresión del Guadalquivir o Valle Bético es una vasta llanura abierta al Océano Atlántico a través de las extensas marismas del río, que apenas se elevan sobre el nivel del mar. Buena prueba de esta planitud es que la ciudad de Sevilla, situada a $100 \mathrm{Km}$ de la desembocadura del Guadalquivir, se encuentra sólo a once metros de altitud. Desde el punto de vista geológico, la Depresión del Guadalquivir es de formación muy reciente: antefosa de las Cordilleras Béticas, se ha ido rellenando con materiales fundamentalmente del Mioceno, y también del Cuaternario. Esta depresión está recorrida de forma disimétrica por el río que le da nombre, pues circula prácticamente adosado a Sierra Morena y deja amplias campiñas en su margen izquierda. Ocupa las partes centrales de las provincias de Jaén, Córdoba y Sevilla, y periféricas de las de Huelva y Cádiz. Es precisamente la Andalucía llana de la Depresión del Guadalquivir, sin apenas accidentes topográficos y con unos suelos en conjunto aptos, cuando no excelentes, para el cultivo, la imagen que más extendida se halla en Andalucía. Pero no puede olvidarse que el Valle Bético apenas ocupa la quinta parte del territorio andaluz.

Finalmente, las Cordilleras Béticas constituyen el conjunto morfoestructural más extenso y complejo de Andalucía. Más extenso, porque afecta a casi dos terceras partes del territorio andaluz, e incide, con disposición ENE-OSO, en buena parte de las provincias de Almería, Granada, Jaén y Málaga, en el sector oriental de la de Cádiz, y en el meridional de las de Córdoba y Sevilla; sólo la provincia de Huelva queda al margen de esta unidad morfoestructural. Y más complejo, por las mismas condiciones de su formación: plegadas durante la orogenia alpina, en ellas se advierten los principales rasgos de las cordilleras de este sistema. De forma esquemática, las Béticas se subdividen en tres alineaciones paralelas, que, de Norte a Sur, son la Prebética, la Subbética y la Penibética, y que van ganando altura en esa misma dirección, hasta alcanzar en el Mulhacén (3.482 metros) la cima de Andalucía. Entre la zona Subbética y Penibética (o Bética, en sentido estricto) se instalan unas altiplanicies interiores de características agronómicas poco uniformes $y$, si bien se encuentran algunas relativamente ricas, como las de Antequera o Granada, en conjunto, por la pobreza de los suelos, la disminución de las precipitaciones y la continentalización de las temperaturas, en ellas se continúa practicando una agricultura difícilmente competitiva con la del Valle Bético.

De esta sucinta panorámica sobre las condiciones del medio físico andaluz -y sin entrar en referencias de carácter climático- se quiere destacar el claro predominio de las áreas de montaña en Andalucía, y éstas no son precisamente las más estimadas por su aptitud agronómica. Asimismo, este medio físico contrastado implica diversidad de aprovechamiento y distintas escalas de productividad. 
En segundo lugar destacábamos al principio la importancia de las transformaciones que recientemente ha experimentado la agricultura andaluza. En el caso que nos ocupa se ha producido, históricamente, una manifiesta disociación entre las transformaciones sufridas en la estructura de la propiedad y los cambios registrados en las técnicas de cultivo e incremento de la productividad. Durante el siglo XIX se asiste — básicamente a través de las leyes desamortizadoras y desvinculantes de la tierra - a la sustitución del sistema de propiedad estamental y feudal por el de propiedad privada y burguesa; sin embargo, se mantienen las mismas técnicas de cultivo y los hijos reproducen los modos de llevar la tierra que vieron practicar a sus padres. Por el contrario, ya en el siglo xx, una vez superado el período postbélico, y sobre todo a partir de la década de los sesenta, la agricultura andaluza experimenta unos cambios sustanciales, tanto en los usos del suelo como en los sistemas de producción, de los que, a título enunciativo, destacamos la intensificación del cultivo en las campiñas, con la desaparición del barbecho como nota dominante y la introducción de nuevas plantas barbecheras; la expansión del regadío, que ofrece la imagen inusual de una Andalucía verde en el período estival, o la aún más insólita de los cultivos bajo plásticos, y, finalmente, las repoblaciones forestales a base de especies nuevas en la región, tales como el eucalipto.

Todo ello nos ha llevado a dividir esta exposición en dos grandes apartados: los paisajes tradicionales y los nuevos paisajes rurales andaluces.

\section{LOS PAISAJES RURALES TRADICIONALES DE ANDALUCIA}

Hasta fecha reciente los paisajes rurales andaluces venían caracterizados por:

a) Los cultivos definidores de la trilogía mediterránea, es decir, cereales - que en el caso andaluz ha sido, y continúa siendo, trigo--, olivar y viñedo. No debe pensarse que los tres ocupan extensiones similares, sino que, por el contrario, se encuentran muy desigualmente representados en el campo andaluz, con claro dominio de la tierra calma, seguida del olivar, mientras que el viñedo ocupa una superficie proporcionalmente muy reducida. Estos cultivos marcan la fisonomía de las campiñas andaluzas, pero están igualmente presentes en la sierra.

b) Con la excepción de los regadíos de la Vega de Granada y hoyas litorales mediterráneas, las tierras regadas en Andalucía poseen escaso desarrollo, por lo que no han de ser consideradas como representativas de la agricultura andaluza tradicional.

c) Los terrenos incultos no han sido, ni mucho menos, privativos de los espacios serranos, aunque tengan en éstos su expresión paisajística dominante. Todavía hoy, después de haber sufrido un duro proceso desforestador, la sierra andaluza conserva bellos paisajes forestales, como los de la cabecera 
del Guadalquivir, o los de la Sierra de Grazalema (Cádiz), pero se encuen. tran más extendidos los paisajes de monte bajo y matorral, con un aprove. chamiento pobre de pastos.

\subsection{Las tierras cerealistas}

El paisaje rural más característico de la Andalucía tradicional es el de las tierras acortijadas dedicadas a los cultivos herbáceos de secano. En ellas se ha seguido un sistema de producción extensivo, de bajos rendimientos por unidad de superficie, basado en el cultivo «al tercio» o de rotación trienal. Las condiciones específicas de la rotación pueden variar de una comarca a otra en función de condicionantes físicos (volumen de agua precipitada, calidad de los suelos...), humanos e históricos; la esencia del sistema reside en la división de las tierras de cada finca en tres tercios (u hojas), una de las cuales se dedica al cultivo, generalmente, de trigo; otra queda como erial, para el aprovechamiento del ganado, y la tercera es la que admite mayor diversificación, tanto por la intensidad de su uso (desde cultivarse pequeñas superficies a sembrarse en su totalidad) como por los cultivos que acoge (todo tipo de cereales, con predominio de la cebada, y leguminosas) (DRAIN, 1977).

En la tierra calma andaluza la producción por excelencia es la triguera, pues, salvo en los suelos de peor calidad, una de las tres hojas se dedica sistemáticamente al cultivo del trigo, de ahí la denominación que también reciben como «tierras de pan llevar». La producción triguera es completada con la de cebada y avena, como principales cereales, y entre las leguminosas, habas y garbanzos. En el Antiguo Régimen esta producción variada, junto a otras menores, garantizaban la alimentación de la población en años de buena cosecha, pero en años malos ocasionaban la carestía de los alimentos, hambre, epidemias, e incluso era la causa directa de levantamientos populares.

Constituye, pues, la tierra calma la base de la organización económica y social en una sociedad eminentemente rural, como lo ha sido la andaluza hasta bien entrado el siglo XX, y así, pues, la distribución de la tierra en propiedades de grandes dimensiones (los latifundios), el trabajo realizado por mano de obra asalariada (los jornaleros) y la elevada concentración del hábitat en núcleos que con frecuencia superan los 10.000 habitantes (los grandes y blancos pueblos andaluces), entre los que se intercalan los señoriales cortijos, completan la imagen de nuestro más difundido paisaje rural.

\subsection{El olivar}

Con frecuencia la agricultura andaluza se identifica más con los campos de olivar que con las tierras cerealistas, que, a fin de cuentas, conforman un paisaje agrario habitual en la Europa no mediterránea. Es el olivar un árbol de amplia tolerancia ecológica, tanto por su adaptación a todo tipo de suelos - aunque se desarrolla mejor sobre los calizos - y a accidentadas topografías como por sus bajas exigencias en humedad, y de forma especial su resistencia a la sequía estival, que, como se sabe, 
constituye el principal factor restrictivo de la agricultura en las zonas de clima mediterráneo. No es de extrañar, pues, la presencia tan significativa de este árbol en ambas orillas del Mediterráneo.

En Andalucía, el olivar se ha extendido por doquier: de la serranía al valle, del interior a la costa, si bien manifiesta marcada preferencia por ciertas comarcas y se convierte en verdadero monocultivo en algunas de ellas (Alto Guadalquivir y Subbético). En tiempos históricos, y por lo que hasta ahora conocemos, se ha ido ampliando progresivamente la superficie dedicada al cultivo del olivar, tendencia que se intensifica en los siglos XVIII y XIX. Este hecho hay que ponerlo en relación, por una parte, por el lugar ocupado por el aceite de oliva en la alimentación andaluza, y por otra, y sobre todo, con el incremento que adquiere su comercialización en el siglo XIX, impulsado además por la abolición de ciertos derechos señoriales (LóPEZ ONTIVEROS, 1974).

Buena parte de este avance del olivar se realiza sobre terrenos que permanecían incultos y que entonces se desbrozan por vez primera, por lo que debeu ser considerados como marginales y escasamente productivos. Incide en esta consideración de marginalidad los repartimientos que sobre terrenos comunales se realizaron durante los siglos XVIII y XIX en pequeños lotes a jornaleros y campesinos. Estas suertes se dedicarán de forma preferente a "plantío de olivar», una vez que fracasen, por sus bajos rendimientos, como tierras cerealistas (CRUZ VILLALÓN, 1980). Esta razón no puede ser olvidada cuando se analice la crítica coyuntura actual del olivar.

\subsection{El viñedo}

De las tantas veces nombrada trilogía mediterránea - trigo, olivar y viñedo-, este último ha ocupado y ocupa en Andalucía una extensión tan reducida, que difícilmente puede concedérsele el rango que poseen los dos anteriores. A finales del XIX, el viñedo cubría una superficie de 105.000 hectáreas (E. R. A., ZoIDO, 1980), y actualmente se aproxima a las 120.000 - que significa algo menos del $3 \%$ de la superficie cultivada-. Estas cifras parecen suficientes para poner de manifiesto que en términos espaciales y paisajísticos el viñedo no puede parangonarse con el olivar, y mucho menos con la tierra calma.

El viñedo, como el olivar, es un arbusto de amplia tolerancia ecológica, que se cultiva en los más variados tipos de suelo, y que, asimismo, resiste las condiciones del estío mediterráneo: altas temperaturas, ausencia de precipitaciones y elevada evaporación. Es por esta razón - junto a otra que no puede ser menospreciada: la función cultural (en el amplio sentido de la palabra), que tradicionalmente ha cumplido el vino- por lo que se encuentran pagos de viñas en un buen número de municipios andaluces, ya sean serranos, campiñeses o litorales, aunque no sumen más de algunas decenas de hectáreas. Así pues, la reducida extensión que el viñedo ha poseído en Andalucía es el resultado - sobre todo con anterioridad a la invasión de la filoxera- de la adición de pequeñas manchas de viñedos presentes por doquier. Si su significado, desde el punto de vista espacial y cuantitativo es bajo, adquiere una mayor relevancia desde el punto de vista cualitativo: por los mayores rendimientos 
que se obtienen por unidad de superficie, por el proceso de transformación al que la uva es sometida in situ, por el alto valor del producto final e, incluso, por el sentido lúdico que se asocia a esta producción agrícola (y buena prueba de ello es la celebración de muchas fiestas locales coincidiendo con la vendimia de la uva).

Otra característica peculiar del viñedo andaluz es que se ha encontrado generalmente en manos de pequeños propietarios. Los cuidados que requiere su cultivo, así como sus mayores rendimientos, en comparación a otros aprovechamientos, han propiciado la asociación viñedo-pequeña propiedad, aunque tampoco quiera decir que esté ausente de la gran propiedad; como más adelante veremos, tras la crisis de la filoxera se asistirá a una concentración espacial y financiera de las plantaciones de vid.

\subsection{Las tierras regadas}

Dentro de los paisajes agrarios tradicionales de Andalucía no puede hablarse como si de una unidad se tratase de las tierras regadas, sino que hay que introducir una clara diferenciación entre las huertas locales y las tierras regadas de las provincias orientales andaluzas. $\mathrm{Si}$ acaso, como rasgo común hay que destacar el régimen de minifundio que domina en las tierras que utilizan el agua como técnica de cnltivo, y puede que ello sea uno de los fundamentos en los que basan su argumentación aquellos que defienden que la introducción del regadio significa de forma casi inmediata la parcelación de las propiedades grandes e incluso medianas. Pero, aparte de esta similitud estructural, dominan en unas y otras rasgos que exigen un tratamiento diferenciado.

En las provincias occidentales andaluzas puede hablarse de una cierta resistencia a la utilización del regadío, situación que sorprende por la disponibilidad de agua que suponen los cursos del Guadalquivir y sus afluentes, y que se ha puesto en relación con la estructura de propiedad latifundista dominante en el Valle Bético (E. R. A., Zoido, 1980). Así pues, el único regadío practicado en estas provincias en términos generales, y salvo contadas excepciones, se reduce a pequeñas huertas de carácter local, orientadas a cubrir las necesidades de hortalizas, frutales y fibras textiles de los núcleos de población. Estas huertas se localizan preferentemente en las proximidades de los pueblos, en su mismo ruedo, y se riegan con agua de pozo, si bien, en las comarcas de la sierra, se sitúan en los fondos de valle y se construyen pequeños embalses para retener el agua de lluvia.

En las provincias orientales diversos factores naturales e históricos han contribuido a una mayor extensión del regadío, de modo que de las 193.000 hectáreas que en Andalucía se regaban a principios del siglo XX, el $90 \%$ se localizaban en ellas, y 106.000 hectáreas sólo en la provincia de Granada (OCAÑA, 1974). La disminución de las precipitaciones - que fuerzan la necesidad del uso del agua en la agricultura-, la elevación de las temperaturas — por la protección que ejercen las Cordilleras Béticas de los vientos del Norte, amén de la acción atemperadora invernal del Mediterráneo- y el deshielo en los meses primaverales, como principales condicionantes naturales, y la más prolongada permanencia de los moriscos en esta 
zona del país, buenos conocedores de las técnicas de riego, entre los factores de orden humano, explican la extensión del regadío en estas provincias.

Esta agricultura se caracteriza porque, junto a la práctica de un policultivo de subsistencia, gran parte de la producción se orienta hacia la comercialización de cultivos filotérmicos, parte de ellos traídos de tierras americanas, y sin competencia en Europa ni en el resto de España, tales como la remolacha azucarera, el tabaco, la caña de azúcar o el lino, entre los cultivos industriales; naranjas, uvas o chirimoyos, entre los frutales (GARCía MANRIQUe, 1972, y VILlEGAS, 1972).

\subsection{Paisajes rurales serranos}

No debe asociarse de forma exclusiva la imagen de los paisajes rurales de la sierra a la de los terrenos incultos, cubiertos por distintas especies arbóreas y arbustivas, y dedicados a un aprovechamiento forestal y ganadero. Ciertamente, los espacios serranos han proporcionado el marco idóneo para el desarrollo de tales actividades, con claro predominio en Andalucía de los ganados de cerda, lanar y cabrío, y destacando como principales especies forestales encina, alcornoque y pino, de las que aún se conservan amplias y muy ricas manchas en nuestras serranías. Pero, además, los espacios montañosos andaluces se han caracterizado tradicionalmente por la presencia de una actividad económica diversificada: campos cultivados de cereal, de largas rotaciones, plantaciones de olivar y viñedo, pequeñas huertas y huertos, orientados, incluso, estos últimos, hacia la comercialización de determinados productos (manzanos, almendros...). Y junto a ellas se han desarrollado otras actividades complementarias, que van desde la explotación de los ricos recursos mineros de la región al florecimiento de actividades artesanales, como las del cuero o el esparto. En los períodos en los que dominan las economías cerradas, el aislamiento de la montaña obliga a esta diversificación de sus actividades productivas y propicia, al mismo tiempo, su «esplendor» económico (E. R. A., CRUZ VILlalóN, 1980) claramente manifestado en el crecimiento demográfico que experimentaron las sierras andaluzas a finales del XVIII y primera mitad del siglo XIX, que ocasionaron que se alcanzaran densidades superiores a la media nacional (RODRÍGUEZ MARTíNEZ, 1977).

La dehesa merece especial atención como paisaje característico de la sierra andaluza, aunque no privativo de ella, pues constituye una unidad paisajística con las de las tierras extremeñas y salmantinas. Las dehesas son explotaciones muy extensivas, cuya fisonomía viene definida por la vegetación característica de encinas y alcornoques. En ellas se combinan y complementan las actividades agrícolas - secundarias, pues su suelo se cultiva cada cuatro, seis o diez años, según sus aptitudes edáficas y condiciones climáticas-, ganaderas - con predominio del ganado de cerda, seguido del lanar y, en última posición, el cabrío- y forestales - producción de una madera de baja calidad, que se dedica generalmente a carboneo, y, sobre todo, la más rica producción de corcho-. Los bajos rendimientos por unidad de superficie - a falta de un conocimiento detallado del proceso de ocupación y poblamiento de estas tierras - han vinculado la dehesa a la propiedad de grandes dimensiones. 
Como resumen de cuanto aquí se ha dicho, habría que incidir en la escasa especialización comarcal que todavía existe en el territorio andaluz, pues aún se conservan amplios espacios incultos en la campiña, de clara vocación agrícola, a la vez que cultivos débilmente productivos se ubican en la sierra.

\section{LOS NUEVOS PAISAJES RURALES ANDALUCES}

Las situaciones anteriormente descritas han dominado en el agro andaluz hasta fechas relativamente recientes. Ciertamente, algunos de los cambios han venido produciéndose de forma insensible y lenta, pero han sido, sin duda, las innovaciones introducidas a partir de los años sesenta las que han significado una completa renovación de los tradicionales paisajes rurales andaluces.

\subsection{Las tierras cerealistas}

Junto a la mecanización generalizada de todas las labores agrícolas, el cambio más radical que se ha registrado ha sido el de la práctica desaparición del barbecho, acompañado de la introducción de nuevas plantas en la alternancia con el trigo y la cebada, y un consiguiente incremento de la producción bruta.

El paso de un sistema de rotación a otro, como lógicamente puede pensarse, no se ha efectuado de forma brusca, sino que lo ha sido de manera continuada y progresiva, iniciándose el proceso en las tierras más fértiles de la campiña y/o pertenecientes a agricultores emprendedores que empiezan a hacer uso de abonos y mecanizan las labores agrícolas. Téngase en cuenta que el sistema de rotación al tercio era un sistema integrado que proporcionaba, por una parte, alimentación para el ganado de labor, y por otra, estiércol, a falta de otros tipos de abono (E. R. A., LóPEZ ONTIVEROS, 1980). La mecanización agrícola y la generalización del uso de abonos químicos ha provocado la pérdida de funcionalidad del sistema de rotación al tercio.

En la actualidad este sistema ha sido sustituido, en la campiña, por otro de rotación bienal con barbecho semillado, en el que el trigo continúa siendo el cultivo principal y alterna con plantas nuevas, de reciente introducción, entre las que destacan algodón, remolacha azucarera, girasol, cártamo y colza, entre otras. Se caracterizan por ser cultivos muy coyunturales, cuya expansión y recesión obedecen a medidas proteccionistas de la política agraria e, incluso, a las oscilaciones del mercado internacional. Algunos han realizado ya el proceso completo, es decir:

a) Introducción novedosa como semilla barbechera.

b) Máxima expansión.

c) Recesión, bien por cambios en la política agraria del país, bien por dificultades de mecanización del cultivo y el consiguiente incremento de los costes salariales.

d) Abandono como cultivo de secano. Tales son los casos del algodón y la remolacha azucarera, cultivos hoy dominantes en las explotaciones de regadío 
de pequeñas dimensiones, en el Valle Bético (CRUZ, OJEDA y ZOIDO, 1980). Actualmente el girasol es el cultivo que tiene más importancia en la alternancia con el trigo, seguido por el cártamo y la colza.

Junto a estas significativas innovaciones no puede ser olvidada la permanencia del trigo como principal producto en la alternativa, pues de las $2.750 .000 \mathrm{Ha}$ dedicadas a su cultivo en España, más de $600.000 \mathrm{Ha}$. se sitúan en Andalucía (que en términos relativos supone el $22 \%$ ), de las que $450.000 \mathrm{Ha}$, en las provincias occidentales. Ello se explica por una política agraria que en España ha protegido de forma continuada la producción triguera, y que beneficia sobremanera a las explotaciones del Valle del Guadalquivir, donde en secano los rendimientos medios superan Ios $2.400 \mathrm{Kg} / \mathrm{Ha}$, cuando la media nacional se encuentra en torno a los $1.600 \mathrm{Kg} / \mathrm{Ha}$. Así pues, estas explotaciones obtienen una renta diferencial, cuando menos, del $50 \%$ superior.

Muy diferente es la situación de los altiplanos del Nordeste, donde una estructura agraria dual (coexistencia minifundio-latifundio) y unas condiciones naturales menos favorables han propiciado la permanencia de un monocultivo cerealista de carácter extensivo (CANO, 1974). Los rendimientos del trigo son incluso inferiores a la media nacional $(1.400 \mathrm{Kg} / \mathrm{Ha})$, y si bien se ha abandonado el sistema de rotación al tercio, el más generalizado es el de «año y vez», en el que a un año que se cultiva trigo o cebada sucede otro de barbecho. Los bajos rendimientos del trigo están ocasionando una reducción de la superficie dedicada a este cultivo y un incremento notorio del de la cebada (JUNTA DE ANDALUCÍA, 1979). De todos modos, no debe pensarse que un medio físico adverso condena a estas comarcas andaluzas a la práctica de una agricultura extensiva y pobre, generadora del paro y la emigración, sino que hay, cuando menos, dos posibilidades para salir de esta situación de marginalidad: el aumento del regadío y la introducción de explotaciones ganaderas para la producción de carne (E. R. A., CANO 1980).

\subsection{El olivar}

El olivar, que había experimentado una expansión continuada, cuando menos, a lo largo de los tres últimos siglos y ampliado su superficie no sólo a costa de los terrenos incultos, sino incluso de la tierra calma, entra en los años sesenta en una crisis profunda, a la que la salida más rápida, y a la vez más drástica, que se le da es el arranque del olivar y su sustitución por otros cultivos; pero esta sustitución a veces se presenta como problemática, y de ahí que muchos agricultores aún confían en una solución que permita la conservación de las plantaciones.

Las causas de la crisis son varias, y se interrelacionan entre sí; entre ellas cabe destacar:

a) La elevación de los costes. - Esta ha sido aducida como la principal causa de la crisis del olivar: un incremento de los'costes, por elevación de los salarios, que no ha sido compensada por un incremento proporcional de los precios percibidos por el agricultor. La recogida manual de la aceituna exige la 
utilización de abundante mano de obra, lo cual no era un handicap cuando los jornaleros recibían salarios muy bajos; pero a comienzos de la década de los sesenta se asiste en el país a un incremento generalizado de los salarios industriales y agrarios, que repercutirá negativamente en la rentabilidad del cultivo del olivar, ya que actualmente entre el 70 y el $80 \%$ de su coste total corresponde a gastos salariales.

b) El atraso tecnológico. - Las innovaciones tecnológicas que han experimentado otros cultivos - desde los frutales al trigo- no se han registrado en el olivar, y prueba de ello es el mantenimiento de la recogida manual de la aceituna (si bien la recolección mecánica por vibrador acabará imponiéndose).

c) Existencia de un olivar marginal. - A lo largo del siglo XIX, empujado por la presión demográfica y la coyuntura alcista del comercio del aceite, el olivar se extendió por tierras de rendimientos mediocres, cuya vocación hubiera sido mejor satisfecha dedicando estas tierras a explotaciones agropecuarias. Hoy, aquellos olivares que produzcan menos de $1.000 \mathrm{Kg} / \mathrm{Ha}$ están llamados necesariamente a desaparecer, y en esta situación se encuentra buena parte del olivar andaluz, ya que rendimientos inferiores a dicho umbral se obtienen en el $31 \%$ del olivar jienense, el mejor olivar andaluz, y afecta hasta el $62 \%$ del olivar malagueño (E. R. A., LópEz ONTIVERos, 1980). La reconversión de estas tierras resulta inevitable.

d) Competencia de aceites de semilla. - Ya se ha hecho mención a la expansión de estas oleaginosas (girasol, cártamo, soja o colza) como plantas barbecheras en alternancia con el cereal, y cuyos costes de producción son sensiblemente más bajos. Si a ello se suma la introducción en el mercado nacional de aceites de semilla producidos fuera del país - en los Estados Unidos, básicamente-, a precios aún más competitivos, de forma que el consumidor dispone en el mercado de aceites de semilla a mitad de precio que el de oliva, se comprenderá fácilmente la progresiva sustitución de este aceite por los anteriores en los hábitos alimenticios del ciudadano medio.

Esta situación ha provocado un acelerado arranque de extensas plantaciones de olivar, y en algunas comarcas se ha perdido en las últimas dos décadas más olivares de los que lentamente se habían venido plantando a lo largo de dos siglos, y, aparte de otras consideraciones, ello ha significado una transformación radical de nuestros paisajes rurales. Donde más rápidamente se ha producido el arranque ha sido en el Valle Bético, pues aquí la sustitución del olivar por cereal, "producción con futuro despejado» (JUNTA DE ANDALUCÍA, 1979), no ofrece dudas; en cambio sí resulta más problemática la reconversión en comarcas marginales, en las que la alternancia más racional y productiva parece ser la explotación ganadera; pero ésta supone elevadas inversiones, nuevas vías de comercialización, mayores riesgos empresariales y utilización de abundante mano de obra: de ahí la permanencia de amplias manchas de olivar no rentable.

En cualquier caso, la crisis olivarera no afecta a todo el olivar andaluz y se asiste, a la vez, a la consolidación de áreas especializadas en su producción: Alto Guadal- 
quivir y Subbético (ORTEGA Alba, 1975). Son estas las comarcas en las que se dan los rendimientos más elevados (más de $2.000 \mathrm{Kg} / \mathrm{Ha}$ ) y en las que se puede hablar, al margen de coyunturas más o menos favorables, de verdadera vocación olivarera.

Desaparición del olivar en las comarcas no rentables e incluso de dudosa rentabilidad (hasta $1.500 \mathrm{Kg} / \mathrm{Ha}$ ) y consolidación como auténtico monocultivo en las más productivas, será la situación en la que desembocará presumiblemente el actual proceso crítico.

\subsection{El viñedo}

Frente al $40 \%$ de la superficie cultivada que hoy se dedica en Andalucía a los cultivos herbáceos de secano, y al 30\% todavía ocupado por el olivar, el viñedo aparece como un cultivo muy secundario, pues, como ya se ha dicho, actualmente cubre unas 120.000 hectáreas, extensión que no alcanza el $3 \%$ de las tierras en cultivo.

Además, el viñedo ha seguido un comportamiento que difiere de los anteriormente descritos, por cuanto que se trata de un cultivo que, en el período que se viene considerando, no ha experimentado unos cambios tan profundos como los observados en las tierras de cereal o en las de olivar.

En el caso del viñedo andaluz las transformaciones de mayor interés se han producido de forma más gradual y se iniciaron en fechas anteriores, tras la recuperación de la crisis filoxérica. Esta hizo su aparición tardía en Andalucía: entró por Málaga en 1878 y no alcanzó al viñedo onubense hasta 1901; poco a poco todos los viñedos fueron atacados por la filoxera, y cuando la enfermedad ha sido superada, no se produce una reconstrucción por igual de las viñas perdidas o afectadas: los pequeños pagos dedicados a la producción vitícola para consumo local han desaparecido en su mayor parte, siendo sustituidos, en muchos casos, por plantaciones de olivar. En cambio, no sólo se han reconstruido, sino que incluso han ganado en extensión las áreas vitícolas orientadas hacia la comercialización y que actualmente se dibujan como comarcas vitícolas monocultivadoras. En tres de ellas (Jerez, en la provincia de Cádiz, con 23.417 hectáreas; el Condado, en la de Huelva, con $18.622 \mathrm{Ha}$, y Montilla-Moriles, en la de Córdoba, con $18.245 \mathrm{Ha}$ ) se localiza el $50 \%$ del viñedo andaluz y se procede a la elaboración de vinos de gran prestigio, que en términos productivos supera ampliamente esa proporción.

Esta concentración espacial del viñedo andaluz — que, de encontrarse disperso por doquier formando pequeñas manchas, se localiza ahora en pocas zonas monocultivadoras - se ha producido de forma simultánea a otra de carácter estructural y financiera. Los pequeños propietarios no pudieron soportar la crisis y sus tierras fueron adquiridas, como en el caso de Jerez de la Frontera, por los comerciantes del sector, que de exportadores, y siguiendo el proceso inverso al de la producción, pasaron a convertirse en propietarios de las viñas (E. R. A., Zoido, 1980). Así pues, al final del proceso se ha impuesto en el territorio andaluz una especialización comarcal y una concentración financiera de la producción vitícola y vinícola. 


\subsection{Las tierras regadas}

Quizás el cambio más espectacular experimentado en la agricultura andaluza en los últimos veinticinco años sea la ampliación de la superficie regada, que hoy se sitúa por encima de las $500.000 \mathrm{Ha}$, es decir, el $13 \%$ de la superficie labrada. La extensión del regadío ha significado, desde el punto de vista paisajístico, una transformación radical, al empezar a ser frecuente la imagen de campos verdes en el período estival, y desde el punto de vista económico, un incremento notable de la producción bruta.

Los rasgos definidores y más característicos de los climas mediterráneos - acusada sequía estival, fuerte irregularidad pluviométrica, tanto ínter como intraanual, temperaturas invernales moderadas y débil riesgo de heladas - invitan a la utilización del regadio como medio de incrementar las posibilidades agrícolas y diversificar la producción; por esta razón, quizás lo más sorprendente sea, como más arriba se indicaba, la tardía introducción del regadío en el Valle del Guadalquivir. En fechas anteriores, el regadío, por iniciativa privada, se hallaba más extendido por las provincias orientales, destacando el caso de Granada; a partir de los años cincuenta, y por iniciativa estatal, a través del Instituto Nacional de Colonización (INC), se emprenden grandes obras para la construcción de embalses y regulación de los cursos fluviales, y se dota a zonas previamente delimitadas de la infraestructura completa para riego. Junto a la intervención estatal, la iniciativa privada ha contribuido también al aumento de la superficie regada en Andalucía. Así pues, atendiendo al origen de la iniciativa y a las características peculiares de cada uno de ellos, se pueden distinguir los siguientes tipos de regadío:

\subsubsection{Arrozal de las Marismas del Guadalquivir}

Las Marismas del Guadalquivir venían sosteniendo desde tiempos medievales un aprovechamiento ganadero, entre ellos el de ganado bravo, sin que se considerara posible un aprovechamiento agrícola. Ya en el siglo XIX hay diversos proyectos para llevar a cabo la desecación de las marismas y la desalinización de los suelos, pero no será hasta los años treinta cuando se inicie con éxito la colonización de estas tierras insalubres. Durante la guerra civil, el gobierno del general Franco impulsó el cultivo del arroz en las marismas sevillanas, al estar la principal zona arrocera del país bajo control del gobierno republicano. A partir de entonces se asocia la marisma al cultivo del arroz (ZOIDO, 1973), con tanto éxito, que hoy Sevilla es la primera provincia productora de arroz de España, con más de 26.000 hectáreas y 160.000 toneladas (en torno al $40 \%$ de la superficie y producción arrocera nacional). Logro también de las últimas dos décadas ha sido la completa mecanización de este cultivo, que de lo contrario no hubiera podido sostenerse por el alza de los costes salariales. De todos modos, no existen perspectivas de expansión arrocera, y no tanto por las condiciones naturales y técnicas de su cultivo, sino porque España es excedentaria en arroz y no produce a precios competitivos en el mercado exterior. 


\subsubsection{Las grandes zonas regables}

Con la declaración de unos fines económicos (incremento de la producción) y sociales (instalación de colonos), el Gobierno en los años cincuenta emprendió una política de creación de grandes zonas regables. Andalucía ha sido una de las regiones más beneficiadas por esta actuación, cuyo resultado ha sido el acondicionamiento de veinticuatro zonas regables, de las cuales dieciocho en la cuenca del Guadalquivir, y la puesta en riego de $200.000 \mathrm{Ha}$. Dentro de Andalucía, las tierras más beneficiadas han sido las del Valle Bético, y más concretamente las de la provincia de Sevilla, ya que de las 200.000 Ha mencionadas, más de 85.000 se localizan en la campiña sevillana.

La actuación del I. N. C. (más tarde I. R. Y. D. A.) ha sido sometida a crítica, al fracasar en sus fines económicos y sociales, o simplemente por no llegar a alcanzarlo, por falta de voluntad política. Analizada desde el punto de vista social, la instalación de colonos sólo se ha realizado sobre una pequeña parte de la superficie puesta en riego (en torno al $20 \%$ ), reservándose la mayor parte a sus antiguos propietarios, principales beneficiarios de esta intervención estatal. Desde el punto de vista económico, estos regadíos se dedican de forma mayoritaria a cultivos herbáceos, tales como trigo, maíz, algodón, remolacha o girasol, que suponen un verdadero derroche del agua, mientras que se rechazan orientaciones más productivas, como podrían ser las explotaciones agropecuarias, en una región tan deficitaria en productos ganaderos, o las de frutales, con miras a su comercialización temprana hacia los mercados urbanos europeos. Y desde los puntos de vista.tanto social como económico, hoy se cuestiona la viabilidad de los lotes distribuidos a los colonos (ROMERO y ZOIDO, 1977; CRUZ, OJEDA y ZOIDO, 1980).

\subsubsection{Cultivos enarenados y bajo plástico}

Más recientemente han hecho su aparición en los regadios litorales nuevas técnicas de cultivo que utilizan un material hasta ahora inédito como soporte de la producción agrícola: el plástico. Este se utiliza tanto para conseguir una elevación de la temperatura del suelo y de la planta cultivada como para evitar la evaporación del agua. De esta forma, y mediante la utilización de abonos y herbicidas en grandes cantidades, por lo que ha recibido el nombre de "agricultura forzada», se obtienen producciones extratempranas y de elevados rendimientos, que alcanzan altas cotizaciones en los mercados urbanos, tanto españoles como europeos. La producción está muy diversificada; destaca la horticultura, fuertemente especulativa; la fruticultura mediterránea y la subtropical (naranjas, uvas, nísperos, aguacates, chirimoyos...) y las plantas ornamentales.

La técnica inicialmente utilizada era la de los enarenados, es decir, el cultivo sobre estiércol protegido por una capa de arena, que más tarde se ha reforzado con la protección del plástico. Este se utiliza bien mediante bandas de plástico, qne se sitúan directamente sobre los surcos, o bien en la construcción de invernaderos permanentes, que han convertido los desérticos paisajes de Almería en un «mar de plástico». Esta agricultura manifiesta ser la más dinámica de la región, $\mathrm{y}$, a pesar de lo 
reducido de las superficies cultivadas mediante tales técnicas, su aportación a la producción final agraria supone el $20 \%$ de toda la andaluza (E. R. A., CALATravA, 1980). De todos modos, no puede pensarse en una expansión sin límites de la agricultura bajo plástico: primero, por la fuerte dependencia del exterior, que significa la práctica de esta agricultura forzada; segundo, por los problemas de saturación de mercado y consecuente descenso de los precios, y tercero, porque, en el caso de la provincia de Almería, se está procediendo a una sobreutilización de las aguas subterráneas, con el consiguiente peligro de agotamiento de la reserva.

No debe pensarse, sin embargo, que en Andalucía la superficie regada haya alcanzado ya su techo, pues si nos atenemos exclusivamente a nucstros recursos hidráulicos, ésta aún podría duplicarse; pero antes hay que canalizar el regadío hacia usos convenientes y dar prioridad a los problemas que plantea la comercialización de sus productos.

\subsection{La reconversión de los espacios serranos}

La entrada en economías de carácter abierto ha traído la decadencia de las economías serranas, que, por su marginalidad, no pueden competir con las producciones de áreas especializadas y que han conseguido abrir vías de comercialización hacia esas comarcas. Así, su producción triguera no puede ya ser competitiva con la de la campiña y se abandona; asimismo se renuncia a las plantaciones de vid; las de olivar continúan, aunque con carácter marginal y de dudosa rentabilidad..., si a ello unimos que la vocación ganadera de la sierra se traduce en pobres cabañas ovinas y cabrías y que el cerdo sufre la peste africana, puede comprenderse la crisis profunda de la sierra andaluza (Roux, 1975), que ha ocasionado la emigración masiva y la casi desertización de ciertas áreas de montaña en Andalucía.

La reconversión y búsqueda de nueva funcionalidad de los espacios serranos pueden orientarse en varias direcciones. En primer lugar, debería apoyarse de forma decisiva la modernización (o implantación) de las explotaciones agropecuarias para la producción de carne, en la que la región es deficitaria; esta orientación exige elevadas inversiones por parte de los empresarios, muchos de los cuales no pueden o no quieren realizar, de ahí la necesidad de incentivos por parte de la Administración. En segundo lugar, se debe situar una política de repoblación forestal con fines diversos: productivos, protectores contra la erosión, e incluso recreativos. Hasta la fecha, la especie más usada en la repoblación, especialmente en Sierra Morena, y animada por la creación de una gran empresa nacional de celulosa en las proximidades de Huelva, ha sido el eucalipto (MÁRQUEZ, 1977). Es ésta una especie apreciada desde el punto de vista productivo, por su rápido crecimiento, pero que cuenta con gran número de detractores, porque ocasiona una elevada acidez en los suelos y la práctica desaparición del sotobosque; por lo que parece más aconsejable realizar la repoblación a base de especies autóctonas, es decir, encina, alcornoque y pino, que bien es cierto que también se están utilizando en otras áreas.

Parece claro, a través de las situaciones descritas, que a lo largo de las transformaciones que se han producido en la agricultura andaluza en las últimas décadas 
se ha ido hacia una especialización espacial en aquellos productos mejor adaptados a las condiciones naturales de cada comarca, y a ello no puede ser ajena la sierra en el proceso de reconversión que precisa. Asimismo, debe ser valorada la función que las áreas de montaña pueden y deben cumplir como espacios de ocio y esparcimiento; para ello se hace necesario prestar mayor atención a la red viaria, que, si ya constituye uno de los talones de Aquiles de la organización interna de Andalucía, en las sierras se caracteriza por su trazado sinuoso, calzadas estrechas y deficiente conservación. La contemplación de esta función supondría un mejor equipamiento en servicios y una diversificación de empleo, que las actividades productivas por sí mismas no pueden garantizar.

Así se comprueba, una vez más, que la reconversión generalizada que están exigiendo los espacios rurales no se encuentra única y exclusivamente en el sector primario. La descripción que hasta aquí se ha hecho de las transformaciones que recientemente ha sufrido la agricultura andaluza no debe llevar a pensar en una fase de esplendor de las actividades agrarias; bien es cierto que, desde el punto de vista productivo, el campo andaluz, aunque tampoco esté sometido a un aprovechamiento óptimo, actualmente está bien explotado: sin embargo sigue generando paro. Esto prueba que habrá que enfocar el problema del campo andaluz dentro de la reconversión y reestructuración de la economía andaluza.

\section{BIBLIOGRAFIA}

\section{Obras generales}

Son escasas las obras que tratan en conjunto la problemática de la agricultura andaluza. Destaca, como trabajo de sintesis y actualizado, que además of rece una extensa bibliografía de consulıa, la obra colectiva:

Estudios Rurales Andaluces (E. R. A.): Las agriculturas andaluzas, Madrid, Ministerio de Agricullura, 1980, $505 \mathrm{pp}$.

Por la información estadistica agraria que recoge a nivel provincial y regional, puede asimismo consultarse:

Junta de Andalucia: Criterios para un desarrollo agrario de Andalucia, Sevilla, Consejería de Agricultura, 1979, 257 pp.

\section{Monografias regionales}

Se relacionan a continuación un conjunto de obras de ámbito comarcal o regional, que constituyen la base bibliográfica de la redacción de este texto, si bien se han utilizado también otras fuentes. El que se haya optado por este corto número de títulos obedece a su entidad, actualidad e interés general; para trabajos y artículos de carácter más específico y detallado se remite a la bibliografía de E. R. A., 1980:

Bernai. et Drain: Les campagnes sevillaines auX XIX-XX siècles. Renovation ou stagnation?, París,

Publications de la Casa de Velázquez, Edit. E. De Boccard, 1975, 126 pp.

Bosque Maurel, J.: Andalucia. Estudios de Geografía Agraria, Granada, Aljibe, 1979, 196 pp.

Cano Garcia, G.: La comarca de Baza, Valencia, Departamento de Geografía, 1974, 523 pp.

Cruz Vitlalón, J.: Propiedad y uso de la tierra en la Baja Andalucia. Carmona, siglos xv'll.xx,

Madrid, Ministerio de Agricultura, 1980, $360 \mathrm{pp}$. 
CRUZ,OJEDA y ZOIDO: «Explotación familiar y estrategias campesinas en los nuevos regadios béticos, en Agricultura y Sociedad, número 17, (1980), pp. 11-67.

Draín, M.: Les campagnes de la province de Sevilla. Espace agricole et societé rurale, Lille, Atelier Reproduction de Theses, 1977, 2 vols., 749 pp.

Fourneau, F.: El Condado de Huelva. Bollullos, capital del viñedo, Huelva, Instituto de Estudios Onubenses, $1975,111 \mathrm{pp}$.

Garcia MANRique, E.: Los cultivos subtropicales de la costa granadina, Granada, publicaciones de la Universidad, $1972,160 \mathrm{pp}$.

Godoy López, L.: La ganadería andaluza, Granada, Instituto de Desarrollo Regional, 1979, 93 pp.

López ONTIVERos, Ag.: El sector olécola y el olivar. Oligopolio y coste de recolección, Madrid, Ministerio de Agricultura, 1978, $216 \mathrm{pp}$.

LóPEz ONTIVeros, Ant.: Emigración, propiedad y paisaje en la campiña de Córdoba, Barcelona, Ariel, $1974,607 \mathrm{pp}$.

Márquez Fernández, D.: La Geo-Economía forestal de Huelva y el dilema de sus eucaliptales, Sevilla, publicaciones de la Universidad, 1977, 269 pp.

Ocaña Ocaña, C.: La Vega de Granada, estudio geográfico, Granada, C. S. I. C. y Caja de Ahorros de Granada, 1974, 545 pp.

Ortega Alba, F.: El Sur de Córdoba. Estudio de Geografia Agraria, Córdoba, Monte de Piedad y Caja de Ahorros de Córdoba, 1975, 2 vols., $931 \mathrm{pp}$.

Rodriguez Martínez, F.: La Serrania de Ronda. Estudio geográfico, Málaga, Caja de Ahorros de Ronda, 1977, 530 pp.

Romero y Zoido: Colonización agraria en Andalucia, Sevilla, Instituto de Desarrollo Regional, $1977,258 \mathrm{pp}$.

Roux, B.: Crisis agraria de la sierra andaluza. Un estudio económico de las empresas ganaderas de la provincia de Huelva, Sevilla, Instituto de Desarrollo Regional, 1975, 275 pp.

Villegas Molina, F.: El Valle de Lecrín. Estudio geográfico, Granada, C. S. I. C., 1972, 348 pp.

Zoido Naranjo, F.: Isla Mínima. Aspectos geográfico-agrarios del arrozal sevillano, Sevilla, Instituto de Desarrollo Regional, 1975, 275 pp. 